\title{
IRRESOLUTE MULTIFUNCTIONS
}

\author{
v. POPA \\ Department of Mathematics \\ Higher Education Institute \\ 5500 - Bacau, Romania \\ (Received February 12, 1987)
}

\begin{abstract}
This paper considers a new class of multifunctions, the irresolute multifunctions. For the irresolute multifunctions we give some theorems of characterizations. Some relations between continuous multifunctions and irresolute multifunctions are established.
\end{abstract}

KEY WORDS AND PHRASES. Quasicontinuous multifunction, irresolute multifunction, strongly continuous multifunction.

1980 AMS SUBJECT CLASSIFICATION CODE. $54 \mathrm{C60}$.

\section{INTRODUCTION.}

In [1] Levine defines a set $A$ in a topological space $X$ to be semi-open if there exists an open set $U \subset X$ such that $U \subset A \subset C 1 U$, where $C 1 U$ denotes the closure of $U$.

The family of all semi-open sets in $X$ is denoted by $S O(X)$. A set is semi-closed if its complement is semi-open. The intersection of all the semi-closed sets containing $a$ set $A$ is the semi-closure of $A$ denoted by $\operatorname{Scl} A$. Also, $\operatorname{Scl}(A)=\operatorname{Scl}(\operatorname{Scl} A), A \subset B$ implies Scl A $\subset \mathrm{Scl}$ B, A $\subset \mathrm{Scl} A \subset \mathrm{Cl} A$ and that $A$ is semi-closed iff $A=S c 1 A[2],[3]$.

The notion of irresolute functions was introduced by Crossley and Hildebrand in [4] in this way:

DEFINITION 1. Let $X$ and $Y$ be two topological spaces. A function $f: X \rightarrow Y$ is irresolute if for each $\mathrm{V} \epsilon \mathrm{SO}(\mathrm{Y}), \mathrm{f}^{-1}(\mathrm{~V}) \epsilon \mathrm{SO}(\mathrm{X})$.

The notion of upper (lower) irresolute multifunctions was introduced by Ewert and Lipski in [5].

DEFINITION 2. Let $X$ and $Y$ be two topological spaces.

(a) A multifunction $F: X \rightarrow Y$ is upper irresolute (u.i.) at a point $x \in X$ if for any semiopen set $W \subset Y$ such that $F(x) \subset W$, there exists a semi-open set $U \subset X$ containing $x$ such that $F(U) \subset W$.

(b) A multifunction $F: X \rightarrow Y$ is lower irresolute (1.i.) at a point $x \in X$ if or any semiopen set $W \subset Y$ such that $F(x) \cap W \neq \phi$ there is a semi-open set $U \subset X$ containing $X$ such that $F(y) \cap \neq \phi, \forall$ y $\epsilon$. 
(c) A multifunction $F: X \rightarrow Y$ is upper (lower) irresolute if it has this property in any point $x \in X[5]$.

Some properties of the lower (upper) irresolute multifunctions are studied in [5].

The notion of quasicontinuous multifunctions was introduced and studied by Banzaru and Crivat in [6].

DEFINITION 3. Let $X$ and $Y$ be two topological spaces. A multifunction $F: X \rightarrow Y$ is quasicontinuous at a point $x \in X$ if for any neighborhood $U$ of $x$ and for any open sets $G_{1}, G_{2} \subset Y$ such that $F(x) \subset G_{1}$ and $F(x) \cap G_{2} \neq \phi$ there exists a non-empty open set $G_{U} \subset U$ such that $F\left(G_{U}\right) \subset G_{1}$ and $F(y) \cap G_{2} \neq \phi, \forall y \in G_{U}$.

The multifunction $F: X \rightarrow Y$ is quasicontinuous if it has this property at any point $x \in X[6]$.

Some properties of quasicontinuous multifunctions are studied in [7], [6] and [8].

DEFINITION 4. Let $X$ and $Y$ two topological spaces. A multifunction $F: X \rightarrow Y$ is irresolute at a point $x \in X$ if for any semi-open sets $G_{1}, G_{2} \subset Y$ such that $F(x) \subset G_{1}$ and $F(x) \subset G_{2} \neq \phi$ there exists a semi-open set $U \subset X$ containing $x$ such that $F(U) \subset G_{1}$ and $F(y) \cap G_{2} \neq \phi, \forall y \in U$.

The multifunction $F: X \rightarrow Y$ is irresolute if it has this property at any point $x \in X$. REMARK 1. If $F: X \rightarrow Y$ is irresolute then $F$ is upper and lower irresolute.

REMARK 2. By. Theorem 1.1 [8] it follows that if $F: X \rightarrow Y$ is irresolute then $F$ is quasicontinuous.

\section{CHARACTERIZATIONS.}

Let $X, Y$ be two topological spaces and let $S(y)$ and $K(y)$ be classes of all non-empty and non-empty compact subsets of $Y$, respectively. For a multifunction $F: X \rightarrow Y$ we will denote

$$
\mathrm{F}^{+}(B)=\{\mathrm{X} \in \mathrm{X}: \mathrm{F}(\mathrm{x}) \subset \mathrm{B}\} ; \mathrm{F}^{-}(\mathrm{B})=\{\mathrm{x} \in \mathrm{X}: \mathrm{F}(\mathrm{x}) \cap \mathrm{B} \neq \phi\}
$$

for any subset $B \subset Y$.

DEFINITION 6. Let $A$ be a set of a topological space X.U is a semi-neighbourhood which intersects $A$ if there exists a semi-open set $V \subset X$ such that $V \subset U$ and $V \cap A \neq \phi$. THEOREM 1. For a multifunction $F: X \rightarrow Y$ the following are equivalent:

1. $F$ is irresolute at $x \in X$.

2. For any semi-open sets $G_{1}, G_{2} \subset Y$ with $F(x) \subset G_{1}$ and $F(x) \cap G_{2} \neq \phi$, there results the relation

$$
x \in \mathrm{C} 1\left\{\operatorname{Int}\left[\mathrm{F}^{+}\left(G_{1}\right) \cap \mathrm{F}^{-}\left(G_{2}\right)\right]\right\} .
$$

3. For every semi-open set. $G_{1}, G_{2} \subset Y$ with $F(x) \subset G_{1}$ and $F(x) \cap G_{2} \neq \phi$ and for any open set $U \subset X$ containing $x$, there exists a non-empty open set $G_{u} \subset U$ such that $F\left(G_{U}\right) \subset G_{1}$ and $F(y) \cap G_{2} \neq \phi, \forall y \in G_{U}$.

PROOF. (1) $\Rightarrow(2)$. Let $G_{1}, G_{2} \in S O(Y)$ with $F(x) \subset G_{1}$ and $F(x) \cap G_{2} \neq \phi$. Then there is $U \in S O(X)$ containing $x$ such that $F(U) \subset G_{1}$ and $F(y) \cap G_{2} \neq \phi, \forall y \in U$, thus 
$x \in U \subset F^{+}\left(G_{1}\right)$ and $x \in U \subset F^{-}\left(G_{2}\right)$. Then $x \in U \subset F^{+}\left(G_{1}\right) \cap{F^{-}}^{-}\left(G_{2}\right)$. Since $U$ is a semi-open set in $X$, then by Theorem $1[1] x \in U \subset C 1$ [Int $U] \subset C 1\left\{\right.$ Int $\left.\left[F^{+}\left(G_{1}\right) \cap F^{-}\left(G_{2}\right)\right]\right\}$.

(2) $\Rightarrow(3)$. Let $G_{1}, G_{2} \in S O(Y)$ be with $F(x) \subset G_{1}$ and $F(x) \cap G_{2} \neq 0$. Then $\mathrm{x} \in \mathrm{C} 1\left\{\operatorname{Int}\left[\mathrm{F}^{+}\left(\mathrm{G}_{1}\right) \cap \mathrm{F}^{-}\left(\mathrm{G}_{2}\right)\right]\right\}$. Let $\mathrm{U} \subset \mathrm{X}$ be any open set such that $\mathrm{x} \in \mathrm{U}$. Then $\mathrm{U} \cap\left[\operatorname{Int} \mathrm{F}^{+}\left(\mathrm{G}_{1}\right) \cap \mathrm{F}^{-}\left(\mathrm{G}_{2}\right)\right] \neq 0$. Since $\operatorname{Int}\left[\mathrm{F}^{+}\left(\mathrm{G}_{1}\right) \cap \mathrm{F}^{-}\left(\mathrm{G}_{2}\right)\right] \subset \operatorname{Int} \mathrm{F}^{+}\left(\mathrm{G}_{1}\right) \cap \operatorname{Int} \mathrm{F}^{-}\left(\mathrm{G}_{2}\right)$ then $U \cap\left[\right.$ Int $F^{+}\left(G_{1}\right) \cap$ Int $\left.F^{-}\left(G_{2}\right)\right] \neq 0$. Put $G_{U}=\left[\operatorname{Int} F^{+}\left(G_{1}\right) \cap\right.$ Int $\left.F^{-}\left(G_{2}\right)\right] \cap U$, then $G_{U} \neq 0, G_{U} \subset U, G_{U} \subset$ Int $F^{+}\left(G_{1}\right) \subset F^{+}\left(G_{1}\right)$ and $G_{U} \subset$ Int $F^{-}\left(G_{2}\right) \subset F^{-}\left(G_{2}\right)$ and thus $F\left(G_{U}\right) \subset G_{1}$ and $F(y) \cap G_{2} \neq 0, \forall y \in G_{U}$.

(3) $\Rightarrow>(1)$. Let $U_{X}$ be the system of the open sets from $X$ containing $x$. For any open set $U \subset X$ such that $x \in U$ and for every semi-open set $G_{1}, G_{2} \subset Y$ with $F(x) \subset G_{1}$ and $F(x) \cap G_{2} \neq 0$, there exists a non-empty open set $G_{U} \subset U$ such that $F\left(G_{U}\right) \subset G_{1}$ and $F(y) \cap G_{2} \neq 0, \forall y \in G_{U}$. Let $W=\underset{U \in U_{x}}{U} G_{U}$, then $W$ is open, $x \in c 1 W, F(W) \subset G_{1}$ and $F(z) \cap G_{2} \neq 0, \forall z \in W$. Put $S=W \cup\{x\}$, then $W \subset S \subset C l W$, thus $W$ is a semi-open set in $X, x \in S, F(S) \subset G_{1}$ and $F(t) \cap G_{2} \neq 0, \forall t \in S$, thus $F$ is irresolute at $x$.

THEOREM 2. For a multifunction $\mathrm{F}: \mathrm{X} \rightarrow \mathrm{Y}$ the following are equivalent:

1. F is irresolute.

2. For every semi-open set $G_{1}, G_{2} \subset Y, F^{+}\left(G_{1}\right) \cap F^{-}\left(G_{2}\right) \in S O(X)$.

3. For every semi-closed set $V_{1}, V_{2} \subset Y, F^{-}\left(V_{1}\right) \cup F^{+}\left(V_{2}\right)$ is a semi-closed set in $X$.

4. For every set $B_{1}, B_{2} \subset Y$, there results the relation

$$
\operatorname{Int}\left\{\mathrm{C} 1\left[\mathrm{~F}^{-}\left(\mathrm{B}_{1}\right) \cup \mathrm{F}^{+}\left(\mathrm{B}_{2}\right)\right]\right\} \subset \mathrm{F}^{-}\left(\mathrm{Scl} \mathrm{B}_{1}\right) \cup \mathrm{F}^{+}\left(\mathrm{Scl} \mathrm{B}_{2}\right) \text {. }
$$

5. For every sets $B_{1}, B_{2} \subset Y$, there results the relation

$$
\operatorname{Sc} 1\left[\mathrm{~F}^{-}\left(\mathrm{B}_{1}\right) \cup \mathrm{F}^{+}\left(\mathrm{B}_{2}\right)\right] \subset \mathrm{F}^{-}\left(\operatorname{Sc} 1 \mathrm{~B}_{1}\right) \cup \mathrm{F}^{+}\left(\mathrm{Scl} \mathrm{B}_{2}\right) \text {. }
$$

6. For every set $B_{1}, B_{2} \subset Y$, there results the relation

$$
\operatorname{sint}\left[\mathrm{F}^{-}\left(\mathrm{B}_{1}\right) \cap \mathrm{F}^{+}\left(\mathrm{B}_{2}\right)\right] \supset \mathrm{F}^{-}\left(\operatorname{sint} \mathrm{B}_{1}\right) \cap \mathrm{F}^{+}\left(\operatorname{sint} \mathrm{B}_{2}\right) \text {. }
$$

7. For each point $x$ of $x$ and for each semi-neighbourhood $v_{1}$ of $F(x)$ and for each semineighbourhood $V_{2}$ which intersects $F(x), F^{+}\left(V_{1}\right) \cap F^{-}\left(V_{2}\right)$ is a semi-neighbourhood of $x$. 8. For each point $x$ of $X$ and for each semi-neighbourhood $v_{1}$ of $F(x)$ and for each semineighbourhood $V_{2}$ which intersects $F(x)$, there is a semi-neighbourhood $U$ of $x$ such that $F(U) \subset V_{1}$ and $F(y) \cap V_{2} \neq 0, \forall y \in U$. 
PROOF. (1) $\Rightarrow(2)$. Let $G_{1}, G_{2} \in S O(Y)$ and $x \in F^{+}\left(G_{1}\right) \cap F^{-}\left(G_{2}\right)$, thus $F(x) \subset G_{1}$ and $F(x) \cap G_{2} \neq 0$, then $F$ being irresolute according to the Theorem 1, implication (1) $\Rightarrow$ (2) there follows that $x \in C 1\left\{\operatorname{Int}\left[\mathrm{F}^{+}\left(G_{1}\right) \cap \mathrm{F}^{-}\left(G_{2}\right)\right]\right\}$ and as $x$ is choosen arbitrarily in $F^{+}\left(G_{1}\right) \cap{F^{-}}^{-}\left(G_{2}\right)$, there follows that $F^{+}\left(G_{1}\right) \cap F^{-}\left(G_{2}\right) \subset \operatorname{Cl}\left\{\operatorname{Int}\left[F^{+}\left(G_{1}\right) \cap F^{-}\left(G_{2}\right)\right]\right\}$ and thus $F^{+}\left(G_{1}\right) \cap F^{-}\left(G_{2}\right)$ is a semi-open set by Theorem 1 of [6].

(2) $\Rightarrow$ (3). For if $V \subset Y$, then $F^{-}(Y-V)=X-F^{+}(V)$ and $F^{+}(Y-V)=X-F^{-}(V)$.

$(3) \Rightarrow(4)$. Suppose that (3) holds and let $B_{1}, B_{2}$ two arbitrary subsets of $Y$, then Scl $B_{1}$ and Scl $B_{2}$ are semi-closed sets in $Y$. Then $F^{-}\left(\operatorname{Scl} B_{1}\right) \cup F^{+}\left(S c 1 B_{2}\right)$ is a semiclosed set of $\mathrm{X}$. By Theorem 1 of [3]

$$
\operatorname{Int}\left\{\mathrm{Cl}\left[\mathrm{F}^{-}\left(\mathrm{Scl} \mathrm{B}_{1}\right) \cup \mathrm{F}^{+}\left(\operatorname{Sc1} \mathrm{B}_{2}\right)\right]\right\} \subset{\mathrm{F}^{-}}^{-}\left(\mathrm{Scl} \mathrm{B}_{1}\right) \cup \mathrm{F}^{+}\left(\mathrm{Scl} \mathrm{B}_{2}\right) \text {. }
$$

Since we have $A \subset \operatorname{Scl} A$ then $F^{+}(A) \subset F^{+}(\operatorname{Scl} A)$ and $F^{-}(A) \subset{F^{-}}^{-}(A) \subset F^{-}(\operatorname{Scl} A)$. Consequent1y,

$$
\begin{aligned}
\operatorname{Int}\left\{C 1 \left[\mathrm{F}^{-}\left(\mathrm{B}_{1}\right)\right.\right. & \left.\left.\cup \mathrm{F}^{+}\left(\mathrm{B}_{2}\right)\right]\right\} \subset \operatorname{Int}\left\{\mathrm{Cl}\left[\mathrm{F}^{-}\left(\operatorname{Scl} \mathrm{B}_{1}\right) \cup \mathrm{F}^{+}\left(\operatorname{Scl} \mathrm{B}_{2}\right)\right]\right\} \subset \\
& \subset \mathrm{F}^{-}\left(\operatorname{Scl} \mathrm{B}_{1}\right) \cup \mathrm{F}^{+}\left(\operatorname{Scl} \mathrm{B}_{2}\right) .
\end{aligned}
$$

$(4) \Rightarrow$ (5). From Sc1 $A=A \cup$ Int $C 1 A$ follows $\operatorname{Sc1}\left[F^{-}\left(B_{1}\right) \cup F^{+}\left(B_{2}\right)\right]=\left[F^{-}\left(B_{1}\right) \cup\right.$ $\left.\mathrm{F}^{+}\left(B_{2}\right)\right] \cup \operatorname{Int}\left\{C 1\left[\mathrm{~F}^{-}\left(B_{1}\right) \cup \mathrm{F}^{+}\left(B_{2}\right)\right]\right\} \subset\left\{\mathrm{F}^{-}\left(B_{1}\right) \cup \mathrm{F}^{+}\left(B_{2}\right)\right] \cup{F^{-}}^{-}\left(\operatorname{Scl} B_{1}\right) \cup \mathrm{F}^{+}\left(\operatorname{Scl} B_{2}\right) \subset$ $\mathrm{F}^{-}\left(\mathrm{Scl} \mathrm{B}_{1}\right) \cup \mathrm{F}^{+}\left(\mathrm{Scl} \mathrm{B}_{2}\right)$.

(5) $\Rightarrow(6) \quad X-\operatorname{sint}\left[F^{-}\left(B_{1}\right) \cap F^{+}\left(B_{2}\right)\right]=\operatorname{Scl}\left[X-F^{-}\left(B_{1}\right) \cap F^{+}\left(B_{2}\right)\right]=$ $=\operatorname{Scl}\left[\left(X-\mathrm{F}^{-}\left(B_{1}\right)\right) \cup\left(X-\mathrm{F}^{+}\left(B_{2}\right)\right)\right]=\operatorname{Scl}\left[\mathrm{F}^{+}\left(Y-B_{1}\right) \cup \mathrm{F}^{-}\left(Y-B_{2}\right)\right] \subset \mathrm{F}^{+}\left(\operatorname{Scl}\left(Y-B_{1}\right)\right)$ $\left.\cup \mathrm{F}^{-}\left(\operatorname{Scl}\left(Y-B_{2}\right)\right)=\mathrm{F}^{+}\left(Y-\operatorname{sint} B_{1}\right) \cup \mathrm{F}^{-}\left(Y-\operatorname{sint} B_{2}\right)=\left(X-\mathrm{F}^{-} \operatorname{sint} B_{1}\right)\right) \cup\left(X-F^{+}\left(\operatorname{sint} B_{2}\right)\right)=$ $X-\left[F^{-}\left(\operatorname{sint} B_{1}\right) \cap \mathrm{F}^{+}\left(\operatorname{sint} B_{2}\right)\right]$ and thus $\operatorname{sint}\left[\mathrm{F}^{-}\left(\mathrm{B}_{1}\right) \cap \mathrm{F}^{+}\left(\mathrm{B}_{2}\right)\right] \supset \mathrm{F}^{-}\left(\operatorname{sint} \mathrm{B}_{1}\right)$ $\cap \mathrm{F}^{+}\left(\right.$sInt $\left.\mathrm{B}_{2}\right)$

$(6) \Rightarrow(7)$. Let $x \in X, v_{1}$ a semi-neighbourhood of $F(x)$ and $v_{2}$ a semi-neighbourhood which intersects $F(x)$, then there exists two semi-open sets $U_{1}$ and $U_{2}$ such that $U_{1} \subset v_{1}$ and $U_{2} \subset v_{2}, F(x) \subset U_{1}$ and $F(x) \cap U_{2} \neq 0$, thus $x \in F^{+}\left(U_{1}\right) \cap{F^{-}}^{-}\left(U_{2}\right)$. By hypothesis $x \in \mathrm{F}^{+}\left(U_{1}\right) \cap \mathrm{F}^{-}\left(U_{2}\right)=\mathrm{F}^{+}\left(\operatorname{sint} U_{1}\right) \cap \mathrm{F}^{-}\left(\operatorname{sint} U_{2}\right) \subset \operatorname{sint}\left[\mathrm{F}^{+}\left(U_{1}\right) \cap \mathrm{F}^{-}\left(U_{2}\right)\right] \subset \operatorname{sint}\left[\mathrm{F}^{+}\left(\mathrm{V}_{1}\right)\right.$ $\left.\cap \mathrm{F}^{-}\left(\mathrm{V}_{2}\right)\right] \subset \mathrm{F}^{+}\left(\mathrm{V}_{1}\right) \cap \mathrm{F}^{-}\left(\mathrm{V}_{2}\right) . \quad$ From $x \in \operatorname{sint}\left[\mathrm{F}^{+}\left(\mathrm{U}_{1}\right) \cap \mathrm{F}^{-}\left(\mathrm{U}_{2}\right)\right] \subset \mathrm{F}^{+}\left(\mathrm{V}_{1}\right) \cap \mathrm{F}^{-}\left(\mathrm{V}_{2}\right)$ it follows that $\mathrm{F}^{+}\left(\mathrm{V}_{1}\right) \cap \mathrm{F}^{-}\left(\mathrm{V}_{2}\right)$ is a semi-neighbourhood of $\mathrm{x}$.

$(7) \Rightarrow(8)$. Let $x \in X, \quad v_{1}$ a semi-neighbourhood of $F(x)$ and $v_{2}$ a semi-neighbourhood which intersects $F(x)$, then $U=F^{+}\left(V_{1}\right) \cap F^{-}\left(V_{2}\right)$ is a semi-neighbourhood of $x$, $F(U) \subset v_{1}$ and $F(y) \cap v_{2} \neq 0, \forall y \in U$. 
(8) $\Rightarrow$ (1). Evident.

COROLLARY 1. For a single valued mapping $f: X \rightarrow Y$ the following are equivalent:

1. $f$ is irresolute at $x$.

2. For each semi-open set $G \subset Y$ with $f(x) \in G$, there results the relation $x \in \operatorname{Cl}\left[\right.$ Int $\left.\mathrm{f}^{-} 1(\mathrm{G})\right]$.

3. For any open set $U \subset X$ containing $x$ and for any semi-open set $G \subset Y$ with $f(x) \in G$, there exists a non-empty open set $G_{U} \subset U$ such that $f\left(G_{U}\right) \subset G$.

COROLLARY 2. For a single valued mapping $f: X \rightarrow Y$ the following are equivalent:

1. $f$ is irresolute.

2. $\mathrm{f}^{-1}(\mathrm{G}) \in \mathrm{SO}(\mathrm{X}), \forall \in \in \mathrm{SO}(\mathrm{Y})$. (Definition $1.1[4]$ ).

3. For each semi-closed set $V \subset Y, f^{-1}(V)$ is a semi-closed set. (Theorem 1.4, [4]).

4. For each subset $B \subset Y$, Int $\left[C l \mathrm{CY}^{-1}(B)\right] \subset \mathrm{f}^{-1}(\mathrm{Scl} B)$.

5. For each subset $B \subset Y, \operatorname{Scl~} f^{-1}(B) \subset f^{-1}(\operatorname{Scl} B)$. Theorem 1.6, [4])

6. For each subset $B \subset Y, \operatorname{sInt} f^{-1}(B) \supset f^{-1}$ (sInt $\left.B\right)$.

7. For each point $x$ of $X$ and for each semi-neighbourhood $V$ of $f(x)$, $f^{-1}(v)$ is a semi-neighbourhood of $x$.

8. For each point $x$ of $x$ and for each semi-neighbourhood $V$ of $f(x)$ there is a semi-neighbourhood $U$ of $x$ such that $f(U) \subset v$.

3. CONTINUOUS MULTIFUNCTIONS AND IRRESOLUTE MULTIFUNCTIONS.

The notion of strongly continuous multifunctions was introduced in [9] as a generalization of the univocal strongly continuous mapping defined by Levine in [10].

DEFINITION 7. The multifunction $\mathrm{F}: \mathrm{X} \rightarrow \mathrm{Y}$ is strongly lower semi-continuous (s.1.s.c.) if for each subset $B \subset Y, \mathrm{~F}^{-}(B)$ is a open set in $X$ [9].

DEFINITION 8. The multifunction $F: X \rightarrow Y$ is strongly upper semi-continuous (s.u.s.c)

if for each subset $B \subset Y, F^{+}(B)$ is an open set in $X$.

THEOREM 3. If $F: X \rightarrow Y$ is a multifunction so that:

1. $F$ is upper irresolute.

2. $F$ is strongly lower semi-continuous, then $F$ is irresolute.

PROOF. Let $G_{1}, G_{2} \in \mathrm{SO}(\mathrm{Y})$. Let $x \in \mathrm{F}^{+}\left(G_{1}\right)$. $F$ being upper irresolute then there is a semi-open set $U$ containing $x$ and $F(U)=G_{1}$. Since $U$ is semi-open in $X$, then by Theorem 1 of [6], $x \in U \subset C 1[$ Int $U] \subset C l\left[\right.$ Int $\left.\mathrm{F}^{+}\left(G_{1}\right)\right]$. As $x$ is chosen arbitrarily in $\mathrm{F}^{+}\left(G_{1}\right)$ there follows that $\mathrm{F}^{+}\left(G_{1}\right) \subset \operatorname{Cl}\left[\operatorname{Int} \mathrm{F}^{+}\left(G_{1}\right)\right]$ and thus $\mathrm{F}^{+}\left(G_{1}\right)$ is a semi-open set in $X$ by Theorem 1 of [1]. F being s.1.s.c. then $F^{-}\left(G_{2}\right)$ is an open set in $X$. Then $\mathrm{F}^{+}\left(\mathrm{G}_{1}\right) \cap \mathrm{F}^{-}\left(\mathrm{G}_{2}\right) \in \mathrm{SO}(\mathrm{X})$ and by Theorem 2, implication (2) $\Rightarrow(1) . \quad \mathrm{F}$ is irresolute.

DEFINITION 9. A multifunction $F: X \rightarrow Y$ is said to be injective if for $x_{1}, x_{2} \in X, x_{1} \neq x_{2}$ we have $F\left(x_{1}\right) \cap F\left(x_{2}\right)=0$.

A multifunction $F: X \rightarrow Y$ is said to be pre-semi-open if for any semi-open set $A \subset X$ the set $F(A)$ is semi-open. 
DEFINITION 10. A set $A$ is called regular open if $A=\operatorname{Int}[\mathrm{Cl} A]$.

THEOREM 5. Let $Y$ be a regular space and $F: X \rightarrow Y S(Y)$ be a pre-semi-open and irresolute multifunction. If one of the conditions holds:

1. Int $F(X)=0$ for every $x \in X$.

2. F is injective,

Then $F$ is lower semi-continuous.

PROOF. In a topological space $(Y, T)$ the intersections of two regular open sets forms a base for a topology $T_{S}$ on $Y$, called the semi-regularization of $T$. If the $Y$ is a regular space then $T=T_{S}$. The proof follows then by Remark 1 and by Theorems 7 and 10 from [5].

THEOREM 6. Let $Y$ be a regular space or a space which has a basis composed of openclosed sets. If $\mathrm{F}: \mathrm{X} \rightarrow \mathrm{K}(\mathrm{Y})$ is a pre-semi-open, irresolute and injective multifunction, then $F$ is continuous.

PROOF. Follows from Remark 1, Theorems 7 and 11 of [5] and Remark 8 from [5].

ACKNOW1EDGEMENT. The author would like to thank the referee for his helpful suggestions toward the improvement of this paper.

\section{REFERENCES}

1. LEVINE, N., Semi-open sets and semi-continuity in topological spaces, Amer. Math. Monthly, 70 (1963, 36-41.

2. BISWAS, N., On characterizations of semi-continuous functions, Atti Accad. Naz. Lincei. Rend. C1. fiz. mat. natur., (6), XLVII (1970), 399-402.

3. NOIRI, T., On semi-continuous mappings, Atti. Accad. Naz. Lincei. Rend. Cl. Sci. fiz. mat. natur., LIV (1973), 210-214.

4. CROSSLEY, S.G. and HILDEBRAND, S.K., Semi-topological properties, Fund. Math., LXXIV (1972), 233-254.

5. EWERT, J., and LIPSKI, T., Quasi-continuous multi-valued mappings, Math. Slevaca, 33 (1983), 69-74.

6. BANZARU, T. and CRIVAT, N. Structures uniforms sur l'espace de parties d'un espace uniforme et quasi-continuite des applications multiveques, Bul. st. Tehn. Inst. Politehn. "T. Vuia". Timisoara, Matem. Fiz. Mec. Teer. Applic. 20 (34), 2(1975), 135-136.

7. BANZARU, T., Sur la quasicontinuite des applications multiveques, Bul. st. Tehn. Inst. Politehn. "T.Vuia". Timisoara. Matem. Fiz. Mec. Teer. Aplic. 21(35), 1(1976), 7-8.

8. POPA, V. Uncle caracterizari ale multifunctiller cvasicontinue si slab continue (Some characterizations of quasicontinuous multifunctions and weakly continuous multifunctions), Stud. Cerc. Mat., 37,1 (1985), 77-82.

9. POPA, V., Multifunctii tari continue (Strongly continuous multifunctions), Bul. st. Tehn. Instit. Politehn. "T. Vuia". Timisoara, Matem. Fiz. 27(41), 1(1982), 5-7.

10. LEVINE, N., Strong continuity in topological spaces, Amer. Math. Monthly, 67 $(1960), 269$.

11. NEUBRUNNOVA, A., On certain generalizations of the notion of continuity, Mat. Casopis, 23,4 (1973), 374-380. 


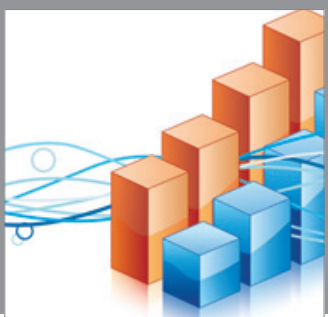

Advances in

Operations Research

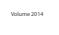

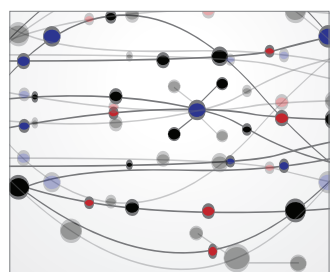

\section{The Scientific} World Journal
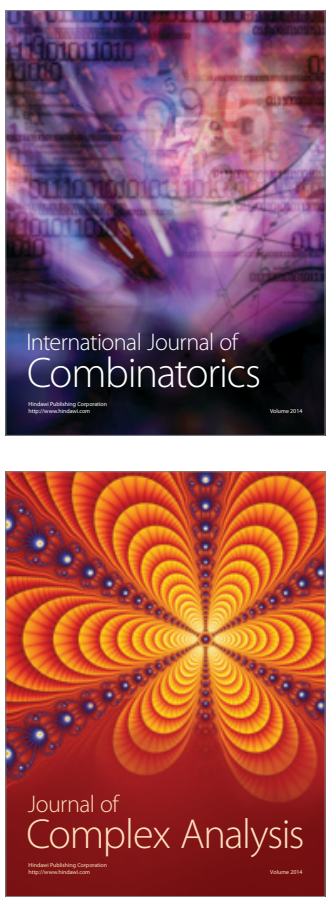

International Journal of

Mathematics and

Mathematical

Sciences
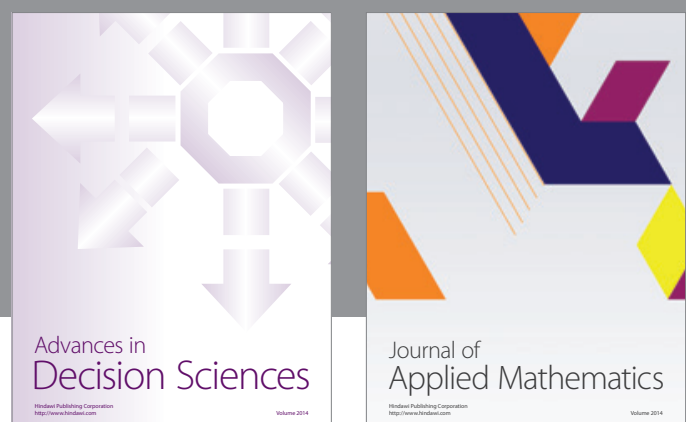

Journal of

Applied Mathematics
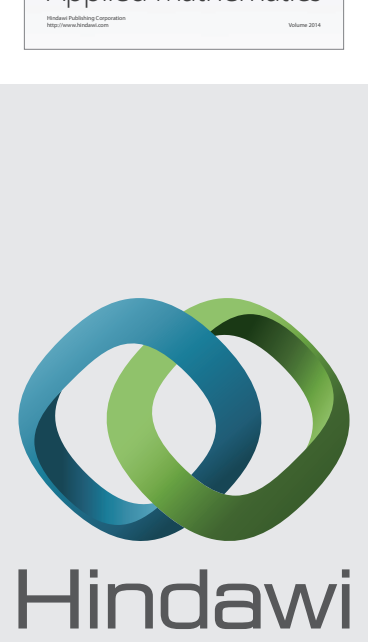

Submit your manuscripts at http://www.hindawi.com
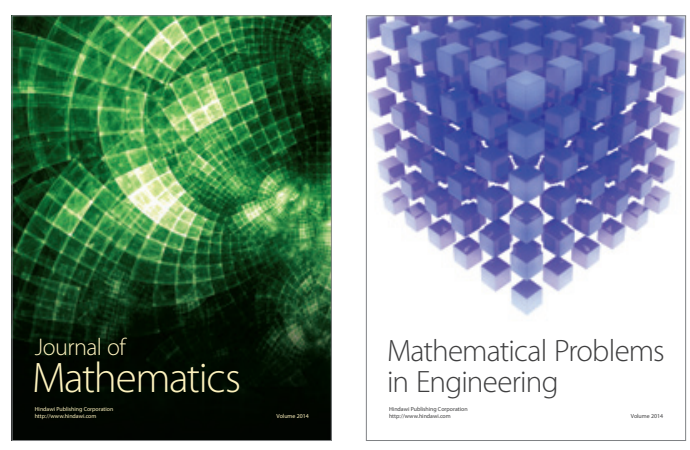

Mathematical Problems in Engineering
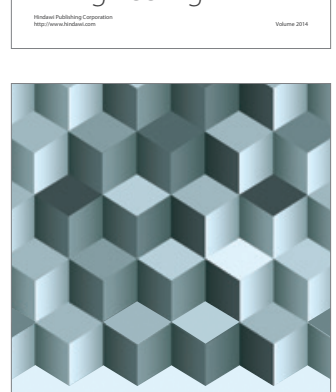

Journal of

Function Spaces
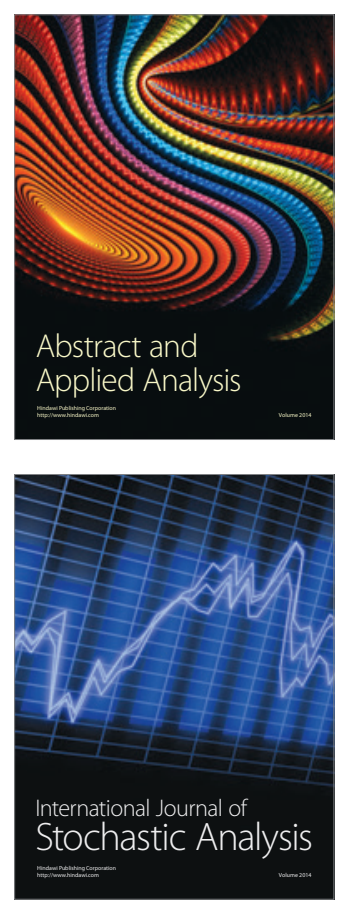

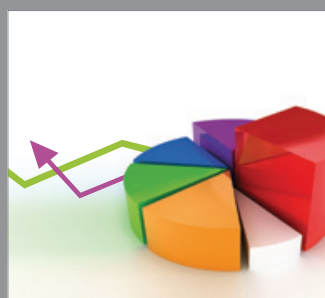

ournal of

Probability and Statistics

Promensencen
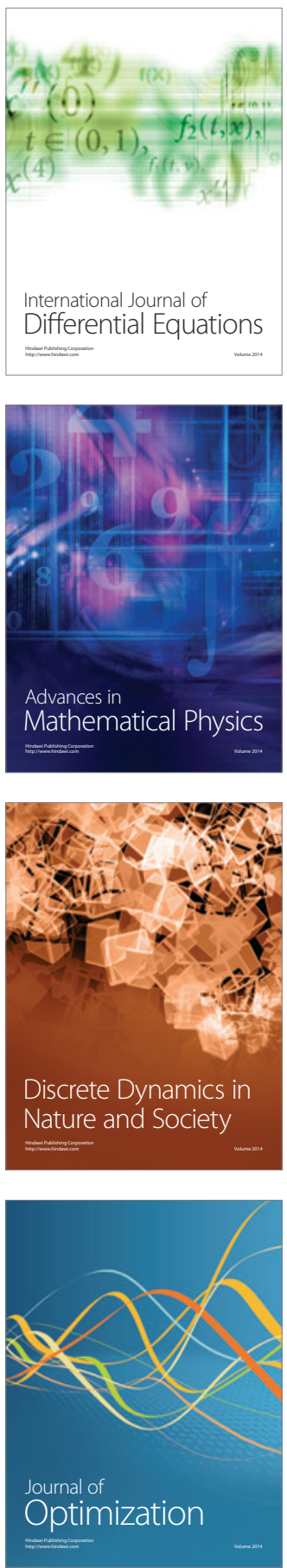